\title{
Does free of charge policy increase care-seeking for children under five in Sierra Leone? Evidence from population-based studies from 2008-2016
}

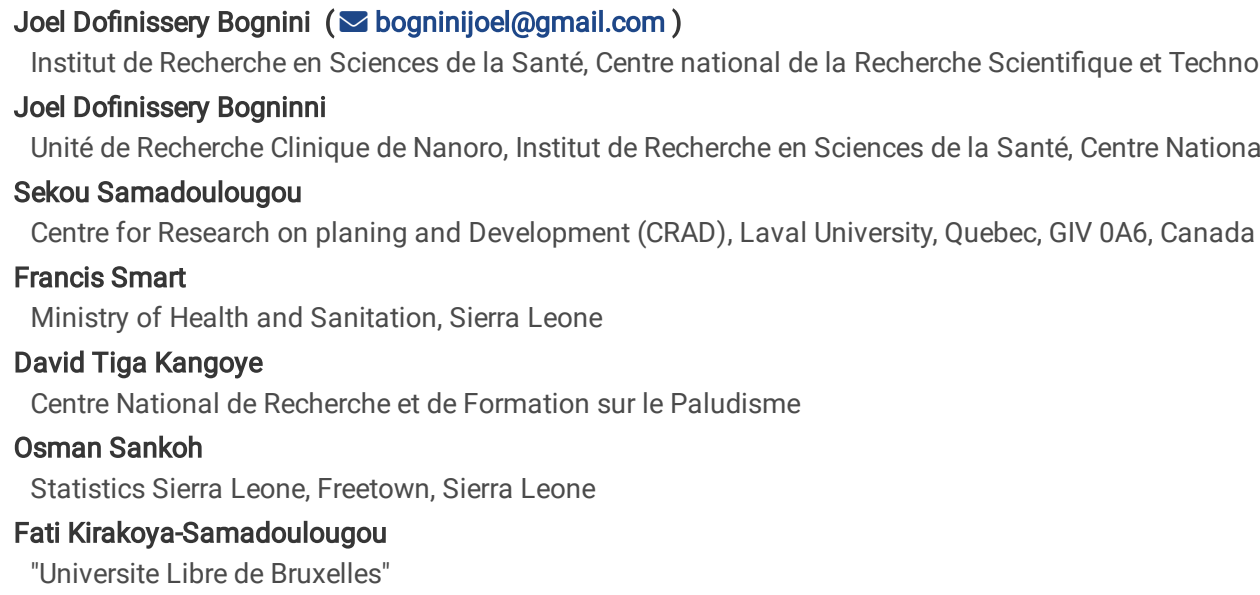




\section{Abstract \\ Background}

In 2010 , the Government of Sierra Leone has implemented the Free Health Care Initiative (FHCl) in the country with the objective to reduce under five mortality. The biggest share of this mortality in the country is attributable to infectious diseases. Care-seeking for children under five is a key point to reduce mortality due to infectious diseases as it permits early diagnosis and prompt and correct treatment. The objective of this study was therefore to assess the trend in the prevalence of care-seeking as well as to identify determinants of utilization of healthcare services by under-five (U5) caregivers under the policy initiative.

\section{Methods}

The analysis of care-seeking behavior was done using data from three population-based studies in Sierra Leone (2008-before FHCl and 2013, and 2016-After $\mathrm{FHCl}$. Care-seeking behavior was assessed through care-seeking of caregivers of children U5 with a history of fever in the 2 weeks prior to the survey. We compared the percentages of care-seeking and performed modified Poisson modeling to evaluate the determinants of care-seeking during the period of FHCl (2013-2016).

\section{Results}

In 2008 , a total of 1,208 feverish children were identified, as compared with 2,823 children in 2013, and 1,633 in 2016 . Fewer children had seeking care for fever in 2008 (51\% [95\% Cl (46.4-55.5)]) than in 2013 (71.5\% [95\% Cl (68.4-74.5)]) and in 2016 (70.3\% [95\% Cl (66.6-73.8)] (p< 0.001)). Care-seeking was low when the household head was a man, when the head of the household was 15-24 years old, when the child was living in a poorest household, in north or west region and when the child was more than one year old.

\section{Conclusions}

The increase of care-seeking in children under five with fever coincided with the initiation of the $\mathrm{FHCl}$ in Sierra Leone. Effective interventions to improve the health facilities' visitation of the children under five should target the identified factors.

\section{Background}

A substantial progress was made in the control of the global under-five mortality rate with a $49 \%$ decline achieved in 18 years, from 2000 ( $76 \%$ ) to 2018 $(39 \%)$. The biggest share of this mortality ( $41.3 \%)$ is attributable to infectious diseases among which the leading killers - pneumonia (12\%), diarrhea ( $8.3 \%)$, sepsis (7\%) and malaria (5\%) - are preventable and treatable febrile diseases [1]. These diseases in children under the age of five remain a public health problem and constitute a handicap of the good growth of children in low incomes countries, particularly in sub-Saharan Africa countries [2]. It was reported 779 cases of respiratory infections per 100,000 population in 2017, and 1028 million cases of diarrhea every year in childhood [3] in sub-Saharan Africa (SSA). Malaria also affected 213 million people in Africa in 2018 [4]. Sub-Saharan Africa, which housed $50 \%$ of the global under-five deaths in 2018 , still ranks last with a mortality rate (at 78\%o) slightly above the global estimates two decades ago. Sierra Leone at $105 \%$, that being 1.4 times above the regional estimate of mortality rate in children under five [1].

To reduce infectious diseases burden, World Health Organization (WHO) recommends through the integrated management of childhood illnesses, the capacity building of health personnel, the improvement of family and community practices and the strengthening of health systems [5], [6]. In addition, for respiratory and diarrheal diseases, a batch of vaccines has been recommended for children under five years. Other measures among which, the improvement of access to safe drinking water, the utilization of improved sanitation, personal and food hygiene were part of the African countries' programs to address these pathologies. For malaria, there is vector control using insecticide treated mosquito nets (ITNs), indoor home spraying, the prevention of malaria infection using the intermittent preventive treatment in pregnancy (IPTps) and seasonal malaria chemoprevention (SMC) in children under five years [7]. These interventions contribute to reducing the burden of infectious diseases. To be more efficient in the reduction of morbidity and mortality in children under five years, earlier care-seeking at the appropriate place with an adapted treatment is necessary for children under five years. Despite these control and prevention measures implemented in most Sub-Sahara Africa countries including Sierra Leone, the sustainable development goal 3.2 aiming to reduce the mortality of children under five to 25 for 1000 live births by 2030 is far from being achieved [8].

Another implemented strategy to reduce burden of these infections is to increase care seeking behavior for febrile children through universal health coverage as part of the sustainable goals aiming to make available essential health care services for all by reducing out-of-pocket expenses of the household. However the universal health coverage, covers only $50 \%$ of the population in the world [9]. User fees may account for up to $30 \%$ of household income [10]; as a mean to finance the health system, it has been shown to significantly worsen low- and middle-income countries (LMIC) households' financial hardship and reduce access to healthcare services. Other barriers have been reported to reduce care-seeking. It is health facility deterrents, distances of the location to facilities, socio-cultural and gender, knowledge, and information about healthcare. Thus, in Nigeria, it was reported that access to health facility was by foot on difficult

practicable roads in some areas. In Kenya, it was reported mothers perceived the need to be empowered to be able to seek care for their children due to genderrelated barriers. Knowledge about causation and prevention of childhood illnesses, prolonged waiting time, poor communication between staff and patients were also reported to be barriers to health care seeking in Africa and Asia [11, 12]. 
The commitment of African countries to implement universal health coverage leads to the initiative of free health care for the vulnerable population [9]. Sierra Leone implemented free health care for pregnant women, lactating women and children under the age of five in April 2010, covering essential care. This policy by reducing the barrier of health care cost [13], aimed to increase earlier health care seeking and management of illness in children and to reduce mortality rate in children under five years.

Although the $\mathrm{FHCl}$ was launched ten years ago, there is limited data on the pattern of care-seeking in Sierra Leone and there are no published reports describing factors associated with care-seeking behavior in Sierra Leone even when known that care and treatment of the main infectious diseases are free. Such knowledge is crucial in refining public health interventions and therefore needed urgently. Using fever as an indicator of morbidity in children under five this study aims to evaluate the trend in the prevalence of care-seeking for fever as well as to identify determinants of utilization of healthcare services by U5 caregivers in the context of $\mathrm{FHCl}$.

\section{Methods}

Data source: This study used data from the Sierra Leone Demographic and Health Surveys (DHS) of 2008, and 2013 and Malaria Indicator Survey (MIS) of 2016. These were national representative household surveys for which women aged from 15 to 49 years were interviewed. Our study concerned children under the age of five years who had febrile episodes in the two last weeks preceding each survey in Sierra Leone.

Settings: Sierra Leone is a country in West Africa. Its area is $71,740 \mathrm{~km}^{2}$ with an estimated population in 2016 of 7,396,000 inhabitants [14]. The climate is tropical with vegetation ranging from savannah to forest. Sierra Leone is divided into 4 administrative regions: the north, east, south and west region. These regions are subdivided into 14 districts. The health system is organized into three levels; Primary Health Care (PHC) with Peripheral Health Units (PHUs): 229 Community Health Centers (CHC), 386 Community Health Posts (CHPs) and 559 Maternal and Child health Posts (MCHPs). The Secondary level is made up of 21 district hospitals [15]. The Tertiary level includes regional and specialized hospitals. There are six hospitals in a Teaching Hospitals Complex established by Act of Parliament. There are several private clinics and hospitals spread across the fourteen districts of the country. The wealth index is not distributed equally within the rural and urban areas. About $61 \%$ of the population in the urban area are richest and in the rural area, 28\% are poorest [16].

Variables: The outcome variable was the proportion of children under five years of age who caregivers sought care during the feverish illness in the last two weeks preceding the survey.

Independent variables included those for the description of the socio-demographic and those for the assessment of the determinants of the care-seeking for fever: the respondent's age ([15-24], [25-34], and $\geq 35$ years); the level of education of the mother of the child (none formal level of education, primary, and secondary or higher level of education); the number of children ever born in the household ([1-2], [3-4] and 5 $\geq$ children); the gender of the household head of the child; the age of the head of the household of the child ([15-24], [25-34], and $\geq 35$ years); the wealth index (richest, richer, middle, poor and poorest); the regions (east, north, south, and west); the place of residence (urban or rural); the religion (Christian, Muslim, traditional and others); the gender of the child; the age of the child (<12, [12-35] and [36-59] months); and the place to seek health care (public, private, traditional and others).

Sampling method: The three Sierra Leone population-based surveys used a two stages cluster sampling method. Enumeration areas (EAs) were constructed with complete coverage of the country. Each EA includes several households. At the first stage, EAs were selected with stratified probability proportional to sample size. The place of residence (urban or rural) was used to stratify EAs. At the secondary stage, households were selected from the EAs using systematic random sampling. The frames were developed based on the 2004 census for the surveys of 2008 and 2013 , the census of 2015 for the 2016 [ $16-18$ ]. Overall 1,208 children under five years of age with fever were included in our study in $2008,2,823$ in the 2013 survey, and 1,633 in the 2016 survey.

Statistical methods: Statistical analyses were performed using Stata version 15.0. We first described the characteristics of the parents of the children and those of the children with fever during the two weeks preceding the survey. Chi-square for trend was used to assess differences between participants' characteristics over the surveys. Analyses were done separately to evaluate the trend of the care-seeking for fever in the three surveys; 2008,2013 , and 2016 for children under five. The descriptive analyses were weighted for probability sampling and considering stratification and clustering, as is standard in all surveys. We compared the percentages of care-seeking between the three surveys and performed a modified Poisson regression model using a Generalize Estimating Equations (to take into account the clustering effect) to evaluate the determinants of care-seeking under the $\mathrm{FHCl}(2013-2016)$.

\section{Results}

Characteristics of the study population: Table 1 shows the characteristics of febrile children and those of their parents. In the three surveys, most (more than 45\%) of the women were aged from 25 to 34 old years. The majority (more than 59\%) of women had no level of education across the surveys. The percentage of women who were Muslim was about 75 \% and those who lived in the rural area were more than 65\%. At least $40 \%$ were in the poor and poorest groups through the three surveys. For most (more than $75 \%$ ) households, the head was a man and was aged over 35 years old. The percentage of children aged between 12 to 35 months was at least $45 \%$ over the surveys. About $38 \%$ of children were in the north region.

Table 1: Characteristics of the children's parents and children with fever in the three surveys. 


\begin{tabular}{|c|c|c|c|c|c|c|c|}
\hline \multirow[t]{2}{*}{ Characteristics of the population } & \multirow[b]{2}{*}{$\mathbf{N}$} & \multicolumn{2}{|l|}{2008} & \multicolumn{2}{|l|}{2013} & \multicolumn{2}{|l|}{2016} \\
\hline & & $\mathrm{n}(\%)$ & $\mathbf{N}$ & $\mathrm{n}(\%)$ & $\mathbf{N}$ & $\mathrm{n}(\%)$ & p-value \\
\hline \multicolumn{8}{|l|}{ PARENTS } \\
\hline Age of mother (years) & 1208 & & 2823 & & 1633 & & 0.01 \\
\hline $15-24$ & & $363(28.7)$ & & $784(27.1)$ & & $536(33.45)$ & \\
\hline $25-34$ & & $587(47.4)$ & & $1321(47.7)$ & & $770(45.6)$ & \\
\hline$\geq 35$ & & $258(24.0)$ & & $718(25.2)$ & & $327(20.9)$ & \\
\hline Number of children & 1208 & & 2823 & & 1633 & & 0.35 \\
\hline $1-2$ & \multicolumn{3}{|c|}{$453(35.7)$} & $919(31.8)$ & \multicolumn{3}{|c|}{$496(31.6)$} \\
\hline $3-4$ & \multicolumn{3}{|c|}{$379(30.8)$} & $869(31.4)$ & \multicolumn{3}{|c|}{$511(31.9)$} \\
\hline$\geq 5$ & \multicolumn{3}{|c|}{$376(33.5)$} & 1035(36.8) & \multicolumn{3}{|c|}{$626(35.6)$} \\
\hline Mother's education level & 1208 & & 2823 & & 1633 & & $<0.001$ \\
\hline None & \multicolumn{3}{|c|}{$830(72.5)$} & 1929(68.1) & \multicolumn{3}{|c|}{$986(59.4)$} \\
\hline Primary & \multicolumn{3}{|c|}{ 190(13.9) } & $411(14.8)$ & \multicolumn{3}{|c|}{$252(15.1)$} \\
\hline Secondary or higher & \multicolumn{3}{|c|}{ 188(13.6) } & $483(17.1)$ & \multicolumn{3}{|c|}{$395(25.5)$} \\
\hline Gender of the household head & 1208 & & 2823 & & 1633 & & 0.02 \\
\hline Male & \multicolumn{3}{|c|}{$972(81.4)$} & $2121(75.8)$ & \multicolumn{3}{|c|}{$1264(77.6)$} \\
\hline Female & \multicolumn{3}{|c|}{$236(18.6)$} & $702(24.2)$ & & $369(22.5)$ & \\
\hline Age of the household head(years) & 1208 & & 2823 & & 1628 & & 0.55 \\
\hline $15-24$ & & $36(2.8)$ & & $102(3.8)$ & & $53(3.2)$ & \\
\hline $25-34$ & & $301(22.9)$ & & $671(23.7)$ & & $365(21.6)$ & \\
\hline$\geq 35$ & & $871(74.3)$ & & $2020(72.5)$ & & $1214(75.2)$ & \\
\hline Wealth index & 1208 & & 2823 & & 1633 & & 0.88 \\
\hline Poorest & & $237(21.4)$ & & $654(22.8)$ & & $444(22.8)$ & \\
\hline Poor & & $219(21.4)$ & & $573(21.1)$ & & $413(23.1)$ & \\
\hline Middle & & $246(21.2)$ & & $574(20.4)$ & & $364(21.7)$ & \\
\hline Riche & & $260(18.8)$ & & $618(20.0)$ & & $271(19.0)$ & \\
\hline Richest & & $246(17.2)$ & & $404(15.6)$ & & $141(13.4)$ & \\
\hline Region & 1208 & & 2823 & & 1633 & & 0.60 \\
\hline East & & 296(18.1) & & $561(22.1)$ & & $346(24.5)$ & \\
\hline North & & $397(45.1)$ & & $1255(41.7)$ & & $650(37.8)$ & \\
\hline South & & $282(20.2)$ & & $742(23.5)$ & & $492(24.9)$ & \\
\hline West & & $233(16.7)$ & & $265(12.7)$ & & $145(12.8)$ & \\
\hline Place residence & 1208 & & 2823 & & 1633 & & 0.09 \\
\hline Urban & & $437(27.5)$ & & $856(27.1)$ & & $436(35.1)$ & \\
\hline Rural & & $771(72.5)$ & & 1967(72.9) & & 1197(64.9) & \\
\hline Religion & 1208 & & 2823 & & 1633 & & $<0.001$ \\
\hline Muslim & & $915(79.5)$ & & $2349(84.3)$ & & $1246(74.6)$ & \\
\hline Christians & & $278(19.2)$ & & $468(15.4)$ & & $383(25.2)$ & \\
\hline Traditional/others & & 15(1.3) & & $6(0.4)$ & & $4(0.2)$ & \\
\hline CHILDREN & & & & & & & \\
\hline Gender of the child & 1208 & & 2823 & & 1633 & & 0.56 \\
\hline Male & & $627(51.4)$ & & $1414(50.6)$ & & $801(49.9)$ & \\
\hline Female & & $581(48.6)$ & & $1409(49.4)$ & & $832(50.1)$ & \\
\hline Age (months) & 577 & & 1371 & & 1633 & & $<0.001$ \\
\hline$<12$ & & $155(27.8)$ & & $305(21.7)$ & & $335(20.6)$ & \\
\hline $12-35$ & & $280(48.2)$ & & $614(45.7)$ & & $753(45.1)$ & \\
\hline $36-59$ & & $142(23.9)$ & & $452(32.5)$ & & $545(34.4)$ & \\
\hline
\end{tabular}

Trends of the prevalence of the care-seeking for fever: Figure 1 summarizes the trends of care-seeking for fever in children under five years of age in the two last weeks preceding each survey. The care-seeking for fever increased from 51\% [95\% CI (46.4-55.5)] in 2008 to 71.5\% [95\% CI (68.4-74.5)] in 2013 but decreased to 70.5\% [95\% CI (66.6-73.8)] in 2016 relatively to 2013. In $2019 *$ an increase was noted in the care-seeking of children under five, about 75.4 [95\% CI (73.3-77.6)] (SLDHS-2019) [19].

\section{Figure 1}

The care-seeking in the public health centers increase from 59.5\% [95\% CI (53.4-65.3)] in 2008 to 84.5\% [95\% CI (81.8-86.9)] in 2013 to 86.8\% [95\% CI (83.9-89.3)] in 2016. In 2019* (SLDHS-2019) [19], the care-seeking in the public health centers was 87.5\% [95\% CI (85.489.4)] (Figure 2).

\section{Figure 2}

In 2008, the care-seeking for fever was high in the west and south regions respectively 68.4\% [95\% CI (60.7-75.1)] and 61.8\% [95\% CI (53.9-69.8)]. Although, a decrease of the care-seeking for fever was noted in the western region from 68.4\% [95\% CI (60.7-75.1)] in 2008 
to $56.6 \%$ [95\% CI (43.4-68.8)] in 2016.

Care-seeking prevalence was 1.5 times higher in 2013 than in 2008 (prevalence ratio,1.48; 95\% CI,1.33 to 1.65; p<0.001), and 1.4 times higher in 2016 than in 2008 (prevalence ratio, 1.43; 5\% CI, 1.28 to 1.59; p<0.001) after adjustment for mothers age, mother 's education level, the gender of the household head, religion and the age of the children (Table 2).

Table 2: Comparing the prevalence of care-seeking between the three surveys prevalence adjusted for characteristics of caregivers and children

\begin{tabular}{|c|c|c|c|}
\hline \multirow[b]{2}{*}{ Characteristics } & \multicolumn{3}{|c|}{ All the surveys } \\
\hline & Adjusted PR** & $95 \% \mathrm{CI}$ & p-value \\
\hline \multicolumn{4}{|l|}{ Year of the survey } \\
\hline 2008 & 1 & & \\
\hline 2013 & 1.48 & $(1.33-1.65)$ & $<0.001$ \\
\hline 2016 & 1.43 & $(1.28-1.59)$ & $<0.001$ \\
\hline \multicolumn{4}{|l|}{ PARENTS } \\
\hline \multicolumn{4}{|l|}{ Age of mother (years) } \\
\hline $15-24$ & 1 & & \\
\hline $25-34$ & 1.01 & $(0.96-1.07)$ & 0.57 \\
\hline$\geq 35$ & 0.93 & $(0.87-0.99)$ & 0.046 \\
\hline \multicolumn{4}{|l|}{ Mother's education level } \\
\hline Secondary or high & 1 & & \\
\hline None & 1.00 & $(0.93-1.07)$ & 0.98 \\
\hline Primary & 1.10 & $(1.04-1.17)$ & 0.001 \\
\hline \multicolumn{4}{|c|}{ Gender of the household head } \\
\hline Female & 1 & & \\
\hline Male & 0.94 & $(0.89-0.99)$ & 0.031 \\
\hline \multicolumn{4}{|l|}{ Religion } \\
\hline Christians & 1 & & \\
\hline Muslim & 1.00 & $(0.94-1.07)$ & 0.82 \\
\hline Traditional/others & 0.96 & $(0.67-1.38)$ & 0.84 \\
\hline \multicolumn{4}{|l|}{ CHILDREN } \\
\hline \multicolumn{4}{|l|}{ Age of the child (months) } \\
\hline$<12$ & 1 & & \\
\hline $12-35$ & 0.93 & $(0.88-0.97)$ & 0.004 \\
\hline $36-59$ & 0.86 & $(0.81-0.91)$ & $<0.001$ \\
\hline
\end{tabular}

Table 3

Determinants of the care-seeking for fever under the free-of-charge policy:

The results presented in table 3 indicated that the gender of the household head, the age of the household head, the socio-economic status, the geographical regions and the age of the child were significantly associated with care-seeking. Care-seeking was low when the household head was a man, when the head of the household was 15-24 years old, when the child living in a poorest household, living in north or west region and when the child was more than one year old.

\section{Discussion}

Using nationally representative health data on children under five living in Sierra Leone, we found that the implementation of the $\mathrm{FHCl}$ in 2010 resulted in a 20 percentage points increase in the prevalence of care-seeking for febrile children. In addition, we identified several determinants of care-seeking behavior relative to children and caregivers of which, the household head gender, the region of residence, and the age of children were the most significant.

Our study revealed that 7 children under five in 10 sought care during fever after the $\mathrm{FHCl}$ when it was only 5 children under five in 10 before. The rise we observed in the prevalence of care-seeking for febrile children following the implementation of the $\mathrm{FHCl}$ in Sierra Leone is in keeping with the findings of Garchitorena et al. in Madagascar, where they found similar increase in the care-seeking in children U5 after two years of free health care initiation [20].

In the present study, considering the period following the implementation of the $\mathrm{FHCl}$, the prevalence of care-seeking for febrile children was lower for households in the poorest quintile. The limited ability of the poorest household to bear the indirect costs of health care is a likely contributor to this difference. 
In addition, recurrent stock-out of drugs and supplies and the resulting out-of-pocket payment incurred by caregivers for health services despite the FHCI [21, 22], contribute to explain this difference between wealth quintiles in terms of care-seeking. A similar finding was reported in a previous study where the increase in the prevalence of care-seeking observed after the abolition of user fees left the most financially vulnerable people behind [13]. Another finding was the higher prevalence of care-seeking when the head of the household was aged over 25 years compared with that of household heads aged less than 25 years. A possible explanation could be a limited experience of young caregivers in the manifestations of childhood diseases as reported in studies conducted in Sierra Leone and Nigeria where the failure to recognize the symptoms of childhood febrile illnesses led to a delay in seeking care or not seeking care at all $[23,24]$.

We also found that children over one year of age had a low prevalence of care-seeking for fever. The same association was found in other studies in Africa $[25,26]$. This could be explained by the fact that the caregivers of older children, having dealt with several episodes of childhood febrile illnesses as the child was aging, may have got experienced in treating fevers without resorting to a public health center.

In the present study, the prevalence of care-seeking for febrile children was lower in male compared to the female-headed households. These results highlight the gender influence at the household decision level in care-seeking decision/behavior for sick children. Care seeking behavior in caregivers of children was reported by Arthur E. in Ghana, Kenya and Zambia to be improved when both parents of the child were involved in the care-seeking decision [27].

In addition, the northern and western regions had low prevalence of care-seeking compared to the eastern region. The population-based surveys in 2013 and 2016 coincided with periods of outbreaks in Sierra Leone. It was the cholera outbreak from 2012 and the Ebola outbreak from 2015. During these outbreaks, the northern and western regions were the most affected [28,29], and population in these regions could have avoided health centers for fear of contamination, this could explain the low prevalence of care-seeking in children under five in the context of free health care observed in our study. In addition, poor road conditions, availability of affordable and reliable transport means, and physical inaccessibility in the rains may contribute to explain the persisting low prevalence in care seeking in these regions despite the free-of-charge policy [30].

We acknowledge some limitations in our study. The study data collection might have been subject to a social desirability bias. Also, some aspects like social networks of the caregivers, the perception of the necessity of the healthcare services, and the causes of the illnesses of the child contributing to explain the care-seeking behavior could be better addressed by the qualitative research which was not included in the population-based surveys we used data for our analyses.

The strengths of this study include the large size of the sample and its representativeness of the population of children under five living in Sierra Leone.

\section{Conclusion}

Our study revealed that the care-seeking for children under five increased significantly after the FHCl implementation in Sierra Leone. Numerous factors including wealth index were found to be associated negatively with care-seeking. Maintaining the $\mathrm{FHCl}$ with adequate strategies to address other barriers beyond financial ones are urgently needed.

\section{List Of Abbreviations}

$\mathrm{CHC}$ : Community Health Care

CHP: Community Health Post

Cl: confidence interval

DHS: Demographic and Health Surveys

EAs: Enumeration Areas

FHCl: Free Health Care Initiative

GEE: Generalized estimating Equations

ICF: International Coach Federation

IPTps: Intermittent Preventive Treatment in pregnancy

ITNs: Insecticide treated of mosquito Nets

$\mathrm{Km}^{2}$ : Kilometer square

MCHP: Maternal and Child Health Post

NA: Not Applicable

PHC: Primary Health Care

PHU: Peripheral Health Units 
PR: Prevalence Ratio

SLDHS: Sierra Leone Demographic and Health Surveys

SMC: Seasonal Malaria Chemoprevention

SSA: Sub-Sahara Africa

U5: under-five

WHO: World Health Organization

\section{Declarations}

Ethical approval and consent to participate in the survey: for the three surveys, the Sierra Leone National Ethics Committee and the International Review Board of International Coach Federation (ICF) have approved the tools to be used and the participant 's consent was obtained before data collection. We have had an authorization from the DHS program to access data on https://dhsprogram.com/data/new-user-registration.cfm.

Consent for publication: Not applicable

Availability of data and materials: The datasets analyzed during the current study are available in the Demographic and Health Surveys program, repository, and accessible after a writing request: https://dhsprogram.com/data/new-user-registration.cfm.

Competing interests: The authors declare they have no competing interest.

Funding: The authors did not receive any founding for this work.

Authors' contributions: KSF and SS contributed to the study conceptualization, KSF and BJD contributed in developing the study design. BJD analyzed the data and wrote the first draft of the manuscript. SKF, SS, KTD, SF and SO contributed to the intellectual content of the manuscript. All authors read and approved the final version of the manuscript.

Acknowledgements: We extend our thanks to DHS Program for providing us with Sierra Leone Demography Health survey data for 2008,2013, and 2016.

Authors' information (optional):

Footnotes: *2019 Data were from the SLDHS report (https://dhsprogram.com/pubs/pdf/PR122/PR122.pdf ), raw data were not available

**Prevalence Ratio

\section{References}

1. UN Inter-agency Group for Child Mortality Estimation. Levels \& trends in child mortality: estimates developed by the UN inter-agency group for child mortality estimation. 2019. https://www.unicef.org/media/60561/file/UN-IGME-child-mortality-report-2019.pdf. Accessed 29 Apr 2020.

2. Sanyang Y. Prevalence of under-five years of age mortality by infectious diseases in West African region. Int J Afr Nurs Sci. 2019;11:100175. doi:10.1016/j.ijans.2019.100175.

3. Troeger C, Blacker BF, Khalil IA, Rao PC, Cao S, Zimsen SR, et al. Estimates of the global, regional, and national morbidity, mortality, and aetiologies of diarrhoea in 195 countries: a systematic analysis for the Global Burden of Disease Study 2016. Lancet Infect Dis. 2018;18:1211-28. doi:10.1016/S14733099(18)30362-1.

4. World malaria report 2019. https://www.who.int/publications-detail/world-malaria-report-2019. Accessed 16 Apr 2020.

5. WHO | Integrated Management of Childhood IIIness (IMCI). WHO. 2017. http://www.who.int/maternal_child_adolescent/topics/child/imci/en/. Accessed 24 Mar 2020.

6. Mason E, Scherpbier R, Lawe-Davies O. WHO position statement on IMCl. The Lancet. 2009;374:782-3. doi:10.1016/S0140-6736(09)61452-5.

7. WHO. Malaria world report 2019. Geneva: World Health Organization; 2019. https://www.who.int/publications-detail/world-malaria-report-2019. Accessed 13 Feb 2020.

8. Goal 3 ... Sustainable Development Knowledge Platform. https://sustainabledevelopment.un.org/sdg3. Accessed 6 Apr 2020.

9. WHO. Primary health care on the road to universal health coverage: 2019 global monitoring report. 2019. https://www.who.int/healthinfo/universal_health_coverage/report/uhc_report_2019.pdf?ua=1.

10. Witter S, Brikci N, Harris T, Williams R, Keen S, Mujica A, et al. The Sierra Leone Free Health Care Initiative (FHCI): process and effectiveness review. 2016. doi:10.13140/RG.2.1.2673.4960.

11. Najnin N, Bennett CM, Luby SP. Inequalities in Care-seeking for Febrile Illness of Under-five Children in Urban Dhaka, Bangladesh. J Health Popul Nutr. 2011;29:523-31. https://www.ncbi.nlm.nih.gov/pmc/articles/PMC3225115/. Accessed 23 Apr 2020.

12. Bedford KJA, Sharkey AB. Local Barriers and Solutions to Improve Care-Seeking for Childhood Pneumonia, Diarrhoea and Malaria in Kenya, Nigeria and Niger: A Qualitative Study. PLoS ONE. 2014;9. doi:10.1371/journal.pone.0100038.

Page $7 / 10$ 
13. Jalloh MB, Bah AJ, James PB, Sevalie S, Hann K, Shmueli A. Impact of the free healthcare initiative on wealth-related inequity in the utilization of maternal \& child health services in Sierra Leone. BMC Health Serv Res. 2019;19:352.

14. WHO | Sierra Leone statistics. WHO. http://www.who.int/countries/sle/en/. Accessed 20 Feb 2020.

15. Ministry of Health and Sanitation. Human Resources for Health Strategy 2017-2021. 2017. https://www.afro.who.int/sites/default/files/201705/hrhstrategy2017.pdf.

16. Statistics Sierra Leone SSL, International ICF. Sierra Leone Demographic and Health Survey 2013. 2014. https://dhsprogram.com/publications/publication-fr297-dhs-final-reports.cfm. Accessed 23 Feb 2020.

17. Statistics Sierra Leone SSL, Macro ICF. Sierra Leone Demographic and Health Survey 2008. 2009. https://dhsprogram.com/publications/publicationfr225-dhs-final-reports.cfm?csSearch=86546_1.

18. Koroma D, Turay M, Moigua M. 2004 population and housing census: analytical report on population projection for Sierra Leone. 2006. https://www.statistics.sl/images/StatisticsSL/Documents/Census/2004/2004_population_and_housing_census_report_on_projection_for_sierra_leone.pd Accessed 23 Feb 2020.

19. Statistics Sierra Leone SSL. Sierra Leone Demographic and Health Survey 2019. 2019. https://dhsprogram.com/pubs/pdf/PR122/PR122.pdf.

20. Garchitorena A, Miller AC, Cordier LF, Rabeza VR, Randriamanambintsoa M, Razanadrakato H-TR, et al. Early changes in intervention coverage and mortality rates following the implementation of an integrated health system intervention in Madagascar. BMJ Glob Health. 2018;3:e000762. doi:10.1136/bmjgh-2018-000762.

21. Witter S, Brikci N, Harris T, Williams R, Keen S, Mujica A, et al. The free healthcare initiative in Sierra Leone: Evaluating a health system reform, $2010-2015$. Int J Health Plann Manage. 2018;33:434-48.

22. Vallières F, Cassidy EL, McAuliffe E, Gilmore B, Bangura AS, Musa J. Can Sierra Leone maintain the equitable delivery of their Free Health Care Initiative? The case for more contextualised interventions: results of a cross-sectional survey. BMC Health Serv Res. 2016;16:258. doi:10.1186/s12913-016-1496-1.

23. Queen A, Isah E, Isara A. Health seeking behaviour among caregivers of under-five children in Edo State, Nigeria. South East Eur J Public Health. 2015;3.

24. Nathaniel-Wurie L, Martin G, Cooper G, Bernier G-LD, Ajayi T, Martineau F, et al. Health-Seeking Behaviour in the Era of Free Healthcare in Urban Slums in Sierra Leone. J Epidemiol Community Health. 2012;66 Suppl 1:A51-A51. doi:10.1136/jech-2012-201753.132.

25. Simieneh MM, Mengistu MY, Gelagay AA, Gebeyehu MT. Mothers' health care seeking behavior and associated factors for common childhood illnesses, Northwest Ethiopia: community based cross-sectional study. BMC Health Serv Res. 2019;19:59. doi:10.1186/s12913-019-3897-4.

26. Lungu EA, Darker C, Biesma R. Determinants of healthcare seeking for childhood illnesses among caregivers of under-five children in urban slums in Malawi: a population-based cross-sectional study. BMC Pediatr. 2020;20:20.

27. Arthur E. The Effect of Household Socioeconomic Status on the Demand for Child Health Care Services. Afr Dev Rev. 2019;31:87-98. doi:10.1111/14678268.12365 .

28. Weyer J, Jansen van Vuren P, Ntshoe G, Ihekweazu C, Msimang V, Blumberg L, et al. Ebola virus disease outbreak in West Africa: one year down the line and the NICD response. NICD Commun Dis Surveill Bull. 2015;13:1-9.

29. WHO. Cholera in Sierra Leone and Guinea. 2012. https://reliefweb.int/sites/reliefweb.int/files/resources/Sierra-Leon_Guinea-Cholera-01sept2012.pdf. Accessed 13 May 2020.

30. Treacy L, Bolkan HA, Sagbakken M. Distance, accessibility and costs. Decision-making during childbirth in rural Sierra Leone: A qualitative study. PLoS ONE. 2018;13. doi:10.1371/journal.pone.0188280.

\section{Table 3}

Table 3: Multivariable modified Poisson regression model to identify factors associated with care-seeking among children under five with fever under the free-of-charge policy, 2013-2016 


\begin{tabular}{|c|c|c|c|c|c|}
\hline Characteristics & Non-adjusted PR** & $95 \% \mathrm{CI}$ & Adjusted PR** & $95 \% \mathrm{CI}$ & p-value \\
\hline \multicolumn{6}{|l|}{ PARENTS } \\
\hline \multicolumn{6}{|l|}{ Age of mother (years) } \\
\hline $15-24$ & 1 & & 1 & & \\
\hline $25-34$ & 0.95 & $(0.9-0.99)$ & 0.99 & $(0.94-1.06)$ & 0.97 \\
\hline$\geq 35$ & 0.90 & $(0.85-0.95)$ & 0.93 & $(0.84-1.01)$ & 0.11 \\
\hline \multicolumn{6}{|l|}{ Mother's education level } \\
\hline Secondary or high & 1 & & 1 & & \\
\hline None & 1.05 & $(0.99-1.10)$ & 1.00 & $(0.93-1.07)$ & 0.83 \\
\hline Primary & 1.09 & $(1.04-1.15)$ & 1.03 & $(0.97-1.10)$ & 0.25 \\
\hline \multicolumn{6}{|l|}{ Number of children } \\
\hline $1-2$ & 1 & & 1 & & \\
\hline $3-4$ & 0.97 & $(0.92-1.01)$ & 0.97 & $(0.91-1.03)$ & 0.40 \\
\hline$\geq 5$ & 0.91 & $(0.87-0.96)$ & 0.97 & $(0.90-1.05)$ & 0.48 \\
\hline \multicolumn{6}{|l|}{ Gender of the household head } \\
\hline Female & 1 & & 1 & & \\
\hline Male & 0.95 & $(0.90-0.99)$ & 0.93 & $(0.88-0.98)$ & 0.014 \\
\hline \multicolumn{6}{|c|}{ Age of the household head (years) } \\
\hline $15-24$ & 1 & & 1 & & \\
\hline $25-34$ & 1.10 & $(0.97-1.24)$ & 1.24 & $(1.06-1.47)$ & 0.007 \\
\hline$\geq 35$ & 1.06 & $(0.94-1.20)$ & 1.21 & $(1.03-1.43)$ & 0.018 \\
\hline \multicolumn{6}{|l|}{ Wealth index } \\
\hline Poorest & 1 & & 1 & & \\
\hline Poor & 1.07 & $(1.01-1.14)$ & 1.11 & $(1.03-.19)$ & 0.004 \\
\hline Middle & 1.14 & $(1.08-1.21)$ & 1.17 & $(1.09-1.26)$ & $<0.001$ \\
\hline Riche & 1.16 & $(1.08-1.24)$ & 1.19 & $(1.09-1.29)$ & $<0.001$ \\
\hline Richest & 1.07 & $(0.99-1.17)$ & 1.13 & $(1.01-1.27)$ & 0.026 \\
\hline \multicolumn{6}{|l|}{ Region } \\
\hline East & 1 & 1 & 1 & & \\
\hline North & 0.87 & $(0.81-0.93)$ & 0.91 & $(0.84-0.98)$ & 0.018 \\
\hline South & 0.92 & $(0.86-0.98)$ & 0.98 & $(0.91-1.06)$ & 0.71 \\
\hline West & 0.85 & $(0.77-0.93)$ & 0.81 & $(0.71-0.92)$ & 0.001 \\
\hline \multicolumn{6}{|l|}{ Place residence } \\
\hline Urban & 1 & & 1 & & \\
\hline Rural & 0.93 & $(0.88-0.98)$ & 0.96 & $(0.90-1.03)$ & 0.28 \\
\hline \multicolumn{6}{|l|}{ Religion } \\
\hline Christians & 1 & & & NA & \\
\hline Muslim & 0.98 & $(0.93-1.03)$ & & NA & \\
\hline Traditional/others & 1.08 & $(0.71-1.64)$ & & NA & \\
\hline \multicolumn{6}{|l|}{ CHILDREN } \\
\hline \multicolumn{6}{|l|}{ Gender of the child } \\
\hline Female & 1 & & & NA & \\
\hline Male & 1.02 & $(0.98-1.05)$ & & NA & \\
\hline \multicolumn{6}{|l|}{ Age of the child (months) } \\
\hline$<12$ & 1 & & 1 & & \\
\hline $12-35$ & 0.94 & $(0.90-0.99)$ & 0.94 & $(0.90-0.99)$ & 0.033 \\
\hline $36-59$ & 0.85 & $(0.80-0.89)$ & 0.85 & $(0.80-0.90)$ & $<0.001$ \\
\hline
\end{tabular}

\section{Figures}




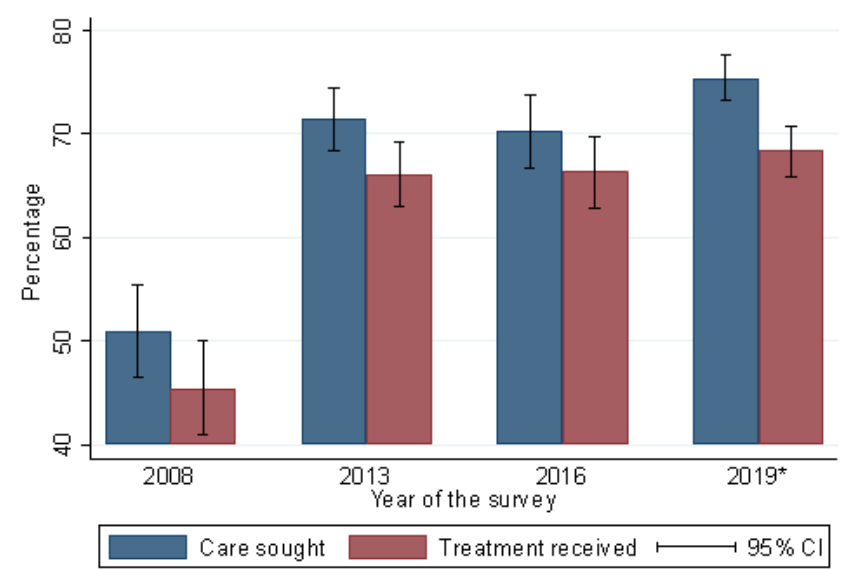

Figure 1: Care sought and treatment received by children under five by survey

Figure 1

[See figure]

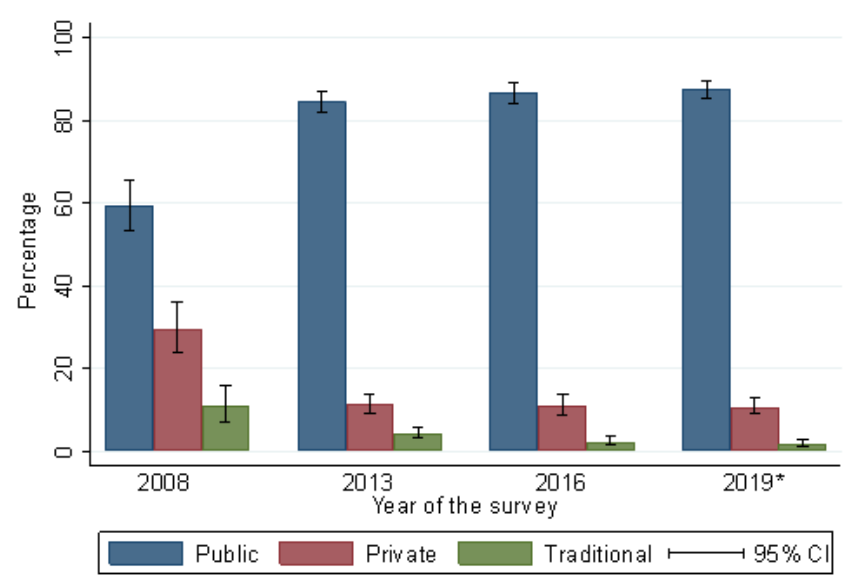

Figure 2: Place of care sought by children under five by survey

Figure 2

[See figure] 